\title{
Genetic Polymorphisms in Glutathione (GSH-) Related Genes Affect the Plasmatic Hg/Whole Blood Hg Partitioning and the Distribution between Inorganic and Methylmercury Levels in Plasma Collected from a Fish-Eating Population
}

\author{
Andréia Ávila Soares de Oliveira, ${ }^{1}$ Marilesia Ferreira de Souza, ${ }^{2}$ \\ André van Helvoort Lengert, ${ }^{2}$ Marcelo Tempesta de Oliveira, ${ }^{2}$ \\ Rossana Batista de Oliveira Godoy Camargo, ${ }^{2}$ Gilberto Úbida Leite Braga, ${ }^{1}$ \\ Ilce Mara de Syllos Cólus, ${ }^{2}$ Fernando Barbosa Jr., ${ }^{1}$ and Gustavo Rafael Mazzaron Barcelos ${ }^{1}$ \\ ${ }^{1}$ Department of Clinical Analyses, Toxicology and Food Sciences, School of Pharmaceutical Sciences of Ribeirão Preto, \\ University of São Paulo, Avenida do Café s/nº, 14040-903 Ribeirão Preto, SP, Brazil \\ ${ }^{2}$ Department of General Biology, Center for Biological Sciences, State University of Londrina, Rodovia Celso Garcia Cid km 380, \\ 86051-990 Londrina, PR, Brazil
}

Correspondence should be addressed to Gustavo Rafael Mazzaron Barcelos; barcelos@fcfrp.usp.br

Received 18 October 2013; Accepted 8 January 2014; Published 18 February 2014

Academic Editor: Wilma De Grava Kempinas

Copyright (c) 2014 Andréia Ávila Soares de Oliveira et al. This is an open access article distributed under the Creative Commons Attribution License, which permits unrestricted use, distribution, and reproduction in any medium, provided the original work is properly cited.

\begin{abstract}
This study aims to evaluate the effects of polymorphisms in glutathione (GSH-) related genes (GSTM1, GSTT1, GSTP1, GCLM, and GCLC) in the distribution of $\mathrm{Hg}$ in the blood compartments in humans exposed to methylmercury (MeHg). Subjects $(n=88)$, exposed to $\mathrm{MeHg}$ from fish consumption, were enrolled in the study. $\mathrm{Hg}$ species in the plasma compartment were determined by LC-ICP-MS, whereas genotyping was performed by PCR assays. Mean total Hg levels in plasma (THgP) and whole blood (THgB) were $10 \pm 4.2$ and $37 \pm 21$, whereas mean evels of plasmatic $\mathrm{MeHg}(\mathrm{MeHgP})$, inorganic $\mathrm{Hg}(\mathrm{IHgP})$, and $\mathrm{HgP} / \mathrm{HgB}$ were $4.3 \pm 2.9$, $5.8 \pm 2.3 \mu \mathrm{g} / \mathrm{L}$, and $0.33 \pm 0.15$, respectively. GSTM1 and GCLC polymorphisms influence THgP and MeHgP (multivariate analyses, $P<0.050$ ). Null homozygotes for GSTM1 showed higher THgP and MeHgP levels compared to subjects with GSTM1 (THgP $\beta=0.22, P=0.035$; $\mathrm{MeHgP} \beta=0.30, P=0.050$ ) and persons carrying at least one $\mathrm{T}$ allele for GCLC had significant higher $\operatorname{MeHgP}(\beta=0.59, P=0.046)$. Also, polymorphic GCLM subjects had lower THgP/THgB than those with the nonvariant genotype. Taken together, data of this study suggest that GSH-related polymorphisms may change the metabolism of MeHg by modifying the distribution of mercury species iin plasma compartment and the $\mathrm{HgP} / \mathrm{HgB}$ partitioning.
\end{abstract}

\section{Introduction}

Mercury ( $\mathrm{Hg})$ exposure during early life is associated with impaired neurodevelopment [1-4] and later in life, with adverse effects on the cardiovascular system $[5,6]$. Fish is the major source of $\mathrm{Hg}$ exposure in fish-eating communities, where the methylmercury $(\mathrm{MeHg})$ is the main species and presents the highest toxicity [7]. In the Amazonian region, several riverside populations, who have fish as the main source of proteins, are chronically exposed to high levels of $\mathrm{MeHg}[8]$.
For biomonitoring $\mathrm{Hg}$ exposure, several biomarkers have been proposed [9-12]. For instance, urinary levels of $\mathrm{Hg}$ frequently estimate the level of exposure to $\mathrm{Hg}$ vapors or inorganic $\mathrm{Hg}(\mathrm{IHg})$ whereas blood $\mathrm{Hg}$ and/or hair Hg predicts $\mathrm{MeHg}$ exposure [13].

According to Lorscheider et al. [14], most of the $\mathrm{MeHg}$ in our body is attached to hemoglobin $(\mathrm{Hb})$ in red blood cells, with a small fraction coupled to GSH that contributes approximately to $1 \%$ of all circulating blood $\mathrm{MeHg}$. Therefore, the use of whole blood as a biomarker of $\mathrm{Hg}$ exposure barely 
reflects available $\mathrm{Hg}$, since only $1 \%$ or less of the metal is in the mobile form ( $\mathrm{Hg}$-cysteine) that effectively reaches the target organs [15]. Due to a higher portion of unbound $\mathrm{Hg}$ in comparison to blood, plasmatic $\mathrm{Hg}$ may be considered a fraction more freely available for exchange with target tissues than $\mathrm{Hg}$ levels in whole blood [16]. In this context, some recent publications demonstrate interesting and relevant associations between plasmatic $\mathrm{Hg}$ and outcomes in $\mathrm{MeHg}$ exposed subjects $[17,18]$.

On the other hand, it is generally accepted that $\mathrm{Hg}$ predominates in plasma in its inorganic form $[19,20]$. However, data supporting this judgment are very limited and based on populations exposed to very low levels of $\mathrm{Hg}$ and only exposed to IHg. Moreover, data on the total plasmatic $\mathrm{Hg}$ /whole blood $\mathrm{Hg}$ ( $\mathrm{THgP} / \mathrm{THgB}$ ) partitioning are totally inexistent for $\mathrm{MeHg}$ exposed populations.

$\mathrm{Hg}$ elimination in humans is linked to the glutathione (GSH) detoxification system in bile and several enzymes of this pathway may be involved in its elimination, such as the glutamyl-cysteine-ligases (GCLs) and the glutathioneS-transferases (GSTs) [21]. Many GSH-related enzymes are highly polymorphic and epidemiological studies have found that some polymorphisms in GSH-related genes are associated with the metabolism of $\mathrm{Hg}$ [22-28] and result in differences of $\mathrm{Hg}$ retention. Moreover, since the polymorphisms of GSH-related genes are associated to differences in $\mathrm{Hg}$ retention in the body, these genetic variations may also modify the partitioning of $\mathrm{Hg}$ between red cells and plasma for a given $\mathrm{Hg}$ whole blood which can be also associated with different toxicologically labile fraction of circulatory $\mathrm{Hg}$.

Then, the aim of the present study was to evaluate the effects of polymorphisms in (GSTM1, GSTT1, GSTP1, GCLM, and GCLC) on the distribution of mercury species ( $\mathrm{MeHg}$ and $\mathrm{IHg}$ ) in the plasma compartment, as well as on the differences in the THgP/THgB partitioning in a group of persons exposed to the metal via consumption of contaminated fish in the Amazonian region of Brazil.

\section{Materials and Methods}

2.1. Study Design and Population. We carried out a crosssectional study with participants from several riverside communities situated on the banks of the Tapajós River, one of the major tributaries of the Amazon River. Recruitment was conducted in 12 villages through a door-to-door invitation followed by community meetings. 88 subjects agreed to participate in the study.

The riverside communities of Brazilian Amazon are different from other populations of Brazil. The persons have a very specific diet; around $80 \%$ of the protein intake comes from fish and the consumption of vegetables and fruits is basically restricted to the region's typical ones [29]. In most of the villages of the study, there are no industrial activities or roads or vehicles, although a few motorized boats are used for fishing and transportation. Moreover, there is no gold-mining close to these communities and no participants reported to have amalgam fillings. Therefore, the only source of $\mathrm{Hg}$ exposure is through the intake of contaminated fish, where $\mathrm{Hg}$ is predominantly found in $\mathrm{MeHg}$ form [8].
Villagers' data were collected using two intervieweradministered questionnaires. One questionnaire covered sociodemographic, life-style, and health information (gender, age, village of residence, place of birth, length of time in the region, educational level, subsistence activities, exposure to other contaminants, frequency and quantity of smoking, drinking and drug habits, medical history and medication). The second was a 7-day recall food consumption frequency questionnaire. For fish consumption, a list was prepared which included most of the fish species present in the region. For each day, participants indicated the number of meals containing fish as well as the fish species that were consumed. Anthropometric measurements (weight, height, and waist circumference) were also taken by a trained technician.

Written consent was provided by all study participants. This study was approved by Ethics Committee of the University of São Paulo at Ribeirão Preto (Brazil), protocol number CEP/FCFRP-71.

2.2. Samples Collection and Hg Analyses. Blood samples were collected in trace metal-free vacuum tubes (BD Vacutainer, Franklin Lakes, NJ, USA) containing heparin. Plasma $\mathrm{Hg}$ species were determined using HPLC-ICP-MS (ELAN DRCII, SCIEX, Norwalk, CT, USA), according the method proposed by Souza et al. [30]. Samples (250 $\mu \mathrm{L}$; in triplicate) were placed in $15 \mathrm{~mL}$ polypropylene test tubes with $2.75 \mathrm{~mL}$ of a solution containing $0.10 \% \mathrm{v} / \mathrm{v} \mathrm{HCl}+0.050 \% \mathrm{~m} / \mathrm{v} \mathrm{L}$-cysteine $+0.10 \% \mathrm{v} / \mathrm{v} 2$-mercaptoethanol and then sonicated for $15 \mathrm{~min}$ in ultrasonic bath (UNIQUE, Brazil). The resulting solution was centrifuged and filtered through $0.20 \mu \mathrm{m}$ Nylon filters (Millipore, USA) and $100 \mu \mathrm{L}$ were injected in HPLC-ICPMS. All separations were performed at room temperature under isocratic conditions. The isocratic mobile phase was $3 \% \mathrm{v} / \mathrm{v}$ methanol $+97 \% \mathrm{v} / \mathrm{v}(0.5 \% \mathrm{v} / \mathrm{v} 2-$ mercaptoethanol + $0.05 \% \mathrm{v} / \mathrm{v}$ formic acid). The flow rate was $1.2 \mathrm{~mL} / \mathrm{min}$. Data evaluation was performed using Chromera software (version 2.1.0.1631) supplied with the instrument, and quantifications were based on peak areas by external calibration. This method determines three species of $\mathrm{Hg}$, but only $\mathrm{MeHg}$ and $\mathrm{IHg}$ were detected in the plasma samples that we analyzed.

$\mathrm{Hg}$ determination of quality control was guaranteed by analyzing standard reference materials from the U.S. National Institute of Standards and Technologies (NIST 966-Toxic Metals in Bovine Blood, certified value $31 \pm 1.7 \mu \mathrm{g} / \mathrm{L}$ and mean found value $31 \pm 0.30 \mu \mathrm{g} / \mathrm{L})$. Moreover, various secondary reference materials, provided by the National Institute of Public Health of Quebec, Canada (INSP External Quality Assessment Scheme (EQAS) for Trace Elements in Blood, Plasma and Hair), were also analyzed. For these reference materials recoveries of $\mathrm{Hg}$ were between 93 and 105\% (based on target values).

2.3. DNA Isolation and Genotyping. Genomic DNA was extracted from peripheral blood using the Easy-DNA kit (Invitrogen, Carlsbad, CA, USA) according to the manufacturer's instructions and stored at $-20^{\circ} \mathrm{C}$ until analyses. GSTM1 and GSTT1 deletions were genotyped using multiplex-PCR as described by Abdel-Rahman et al. [31], with CYP1A1 
(exon 7) as an internal control to ensure good quality of the DNA. The primers, dNTPs, Taq polymerase, and magnesium chloride, were obtained from Invitrogen (Carlsbad, CA, USA). After amplification, PCR products were subjected to electrophoresis on a 2.0\% agarose gel (Invitrogen, Carlsbad, CA, USA) and visualized using ethidium bromide (SigmaAldrich, St. Louis, MO, USA). DNA from samples positive for the GSTM1 and GSTT1 genes yielded bands of 215 and $480 \mathrm{bp}$, respectively, while the internal positive control (CYP1A1) PCR product yielded a $312 \mathrm{bp}$ fragment. GSTP1 $\mathrm{Ile}^{105} \mathrm{Val}$ (rs1695), GCLM-588 (rs41303970), and GCLC-129 (rs17883901) were genotyped by real-time PCR using TaqMan assays (Applied Biosystems, Carlsbad, CA, USA) as described by Custodio et al. [24] on a Quantica Real Time PCR System (TECHNE; Staffordshire, UK).

2.4. Statistical Analysis. Hardy-Weinberg equilibrium was analyzed with the conventional Chi-square test. Age, fish intake, and biomarkers of $\mathrm{Hg}$ were analyzed as continuous variables; gender, genotypes, alcohol consumption, and smoking as categorical variables. We considered participants that consumed at least five drinks per week as alcohol users and smokers those who smoke at least five cigarettes per day for the last five years.

Correlations (Spearman's; rho) were performed in order to examine the associations between age, gender, fish intake, alcohol consumption, smoking, and $\mathrm{Hg}$ biomarkers. After that, Student's $t$-tests were performed to assess the variations between the $\mathrm{Hg}$ biomarkers among the different genotypes.

Finally, multivariate general linear models were employed to evaluate the influence of genetic effects on $\mathrm{Hg}$ biomarkers. In order to adjust for other variables influencing $\mathrm{Hg}$ concentrations, the impacts of age, gender, body mass index, fish intake, alcohol consumption, and smoking on $\mathrm{Hg}$ levels were analyzed in a univariate model and variables were included in the multivariate model if they had a $P$ value $<0.20$, that is, in the present study, age, gender, and fish intake. All $\mathrm{Hg}$ biomarkers were ln-transformed through the analyses, because the nontransformed values were not normally distributed.

Results were defined as statistically significant for a value of $P \leq 0.050$. Analyses were performed using SPSS 20 Statistics software (IBM; Armonk, NY, USA).

\section{Results}

3.1. General Characteristics. Sociodemographic characteristics and $\mathrm{Hg}$ concentrations for all participants enrolled are described in Table 1. The age ranged between 15 and 80 years; the distribution between the sexes was homogenous and fish consumption (portion of fish per day; $150-200 \mathrm{~g}$ per meal) varied from one to four portions per day $(2.5 \pm 1.5)$. Alcohol was consumed by $34 \%$ and $23 \%$ of the study participants were smokers. No participants reported to have amalgam fillings. THgB, THgP, MeHgP, and IHgP were $37 \pm 21,10 \pm 4.3$, $4.3 \pm 2.9$, and $5.8 \pm 2.3 \mu \mathrm{g} / \mathrm{L}$, respectively; $\mathrm{THgP} / \mathrm{THgB}$ ranged from 0.13 to 0.91 .
TABLE 1: General characteristics of riverside persons living in Amazonian region, Brazil.

\begin{tabular}{lcccc}
\hline & $N$ & Mean $\pm \mathrm{SD}$ & Median & Range \\
\hline Participants & 88 & - & - & - \\
Age (years $)$ & 88 & $41 \pm 16$ & 41 & $15-80$ \\
Female/male & $37 / 51$ & - & - & - \\
Body mass index & 88 & $25 \pm 4.6$ & 24 & $17-42$ \\
Portion fish/day & 86 & $2.5 \pm 1.5$ & 3.0 & $1.0-4.0$ \\
$\quad 1$ & 15 & - & - & - \\
2 & 26 & - & - & - \\
$\quad 3$ & 13 & - & - & - \\
$\quad 4$ & 32 & - & - & - \\
$\mathrm{Smoking}^{\mathrm{a}}(\mathrm{yes})$ & $88(20)$ & - & - & - \\
$\mathrm{Alcohol}(\mathrm{yes})$ & $88(30)$ & - & - & - \\
$\mathrm{THgB}^{\mathrm{b}}(\mu \mathrm{g} / \mathrm{L})$ & 88 & $37 \pm 21$ & 29 & $8.4-83$ \\
$\mathrm{THgP}^{\mathrm{c}}(\mu \mathrm{g} / \mathrm{L})$ & 88 & $10 \pm 4.3$ & 9.6 & $2.4-27$ \\
$\mathrm{THgP}^{\mathrm{THHgB}}$ & 88 & $0.33 \pm 0.15$ & 0.29 & $0.13-0.91$ \\
$\mathrm{MeHgP}^{\mathrm{f}}(\mu \mathrm{g} / \mathrm{L})$ & 88 & $4.3 \pm 2.9$ & 3.6 & $0.67-18$ \\
$\mathrm{IHgP}^{\mathrm{e}}(\mu \mathrm{g} / \mathrm{L})$ & 88 & $5.8 \pm 2.3$ & 5.7 & $1.1-13$ \\
\hline
\end{tabular}

ane portion of fish: 150-200 g; two participants did not answer the questionnaire concerning fish intake.

${ }^{\mathrm{b}}$ Total $\mathrm{Hg}$ in blood.

${ }^{\mathrm{c}}$ Total $\mathrm{Hg}$ in plasma.

${ }^{\mathrm{d}}$ Methylmercury in plasma.

${ }^{\mathrm{e}}$ Inorganic $\mathrm{Hg}$ in plasma.

${ }^{\mathrm{f}}$ Ratio between total $\mathrm{Hg}$ in plasma and total $\mathrm{Hg}$ in blood.

Table 2 presents genetic background data and comparative allele frequencies of Caucasians and Africans found in earlier studies (http://www.hapmap.org/, populations CEU; $\mathrm{CEPH}$ (Utah residents with ancestry from northern and Western Europe; and YRI; Yoruba in Ibadan, Nigeria)), because the study population has a genetic background from European colonizers and African slaves. All allelic frequencies were in Hardy-Weinberg equilibrium; in general, for the five polymorphisms analyzed, the genetic/allelic frequencies were more similar to those found in the reference African population than the European ones.

3.2. Correlations between Fish Intake, Lifestyle, and $\mathrm{Hg}$ Biomarkers. Correlations between the variables enrolled in the present work are present in Table 3. Interestingly, here, fish consumption was only positively correlated to $\mathrm{MeHgP}$ $\left(r_{S}=0.32, P<0.0010\right)$. Moreover, THgB, THgP, MeHgP, and IHgP were highly correlated and the highest correlation was found between THgP and MeHgP $\left(r_{S}=0.81, P<0.0010\right)$. Age was positively correlated to $\mathrm{THgB}$, THgP and $\mathrm{IHgP}$, while no correlations were found between $\mathrm{Hg}$ biomarkers and gender. Also, a negative correlation was found between $\mathrm{THgB}$ and THgP/THgB $\left(r_{S}=0.71, P<0.0010\right)$ (Figure 1 ). No correlations were found between smoking and alcohol consumption and $\mathrm{Hg}$ biomarkers.

3.3. Genetic Effects and $\mathrm{Hg}$ Partitioning between Plasma and Whole Blood. Table 4 shows the concentrations of $\mathrm{Hg}$ biomarkers among the different genotypes. It can be seen 
TABLE 2: Genotype, allele frequencies of GSTM1, GSTT1, GSTP1, GCLM, and GCLC polymorphisms of riverside persons living in the Amazonian region of the Tapajós River, Brazil.

\begin{tabular}{|c|c|c|c|c|c|c|}
\hline \multirow{3}{*}{$\begin{array}{l}\text { Genotypes } \\
\text { GSTM1 }\end{array}$} & \multirow{2}{*}{\multicolumn{2}{|c|}{ Genotype frequencies }} & \multirow{2}{*}{\multicolumn{2}{|c|}{$\mathrm{MAF}^{\mathrm{a}}$}} & \multicolumn{2}{|c|}{ Reference MAF } \\
\hline & & & & & \multirow{2}{*}{$\frac{\text { European }}{\text { Null }^{c}}$} & \multirow{2}{*}{$\frac{\text { African }}{\text { Null }^{\mathrm{C}}}$} \\
\hline & Present & Null & - & - & & \\
\hline Deletion & 0.66 & 0.34 & - & - & $0.13-0.54$ & 0.47 \\
\hline GSTT1 & Present & Null & - & - & $\mathrm{Null}^{\mathrm{c}}$ & $\mathrm{Null}^{\mathrm{c}}$ \\
\hline Deletion & 0.60 & 0.40 & - & - & $0.11-0.28$ & 0.37 \\
\hline GSTP1 $\left(\mathrm{Ile}^{105} \mathrm{Val}\right)$ & Ile/Ile & $\mathrm{Ile} / \mathrm{Val}+\mathrm{Val} / \mathrm{Val}$ & $\operatorname{Val}(\mathrm{G})$ & $\mathrm{HWE}^{\mathrm{b}}$ & $\operatorname{Val}(G)^{\mathrm{d}}$ & $\operatorname{Val}(G)^{\mathrm{g}}$ \\
\hline rs1695 & 0.37 & 0.63 & 0.40 & Yes & 0.42 & 0.39 \\
\hline GCLM-588 (C/T) & $\mathrm{CC}$ & $\mathrm{CT}+\mathrm{TT}$ & $\mathrm{T}$ & HWE & $\mathrm{T}^{\mathrm{e}}$ & $\mathrm{T}^{\mathrm{h}}$ \\
\hline rs 41303970 & 0.48 & 0.52 & 0.33 & Yes & 0.10 & 0.25 \\
\hline GCLC-128 (C/T) & $\mathrm{CC}$ & $\mathrm{CT}+\mathrm{TT}$ & $\mathrm{T}$ & HWE & $\mathrm{T}^{\mathrm{f}}$ & $\mathrm{T}^{\mathrm{f}}$ \\
\hline rs17883901 & 0.95 & 0.050 & 0.030 & Yes & 0.060 & 0.010 \\
\hline
\end{tabular}

${ }^{\mathrm{a}}$ Minor allele frequency.

${ }^{\mathrm{b}}$ HWE: Hardy-Weinberg equilibrium. For the GSTM1 and GSTT1 deletions it was not possible to calculate HWE, because the methodology used does not distinguish between hetero- and homozygous genotypes.

${ }^{\mathrm{c}}$ Reference values from Mo et al. [32].

${ }^{\mathrm{d}}$ Reference values for ss1390210 from HapMap-CEU.

${ }^{\mathrm{e}}$ Reference values for ss230641266 from pilot_1_CEU_low_coverage_panel.

${ }^{\mathrm{f}}$ Reference values for ss66860389 from CEU_GENO_PANEL; YRI_GENO_PANEL.

${ }^{g}$ Reference values for ss1390210 from HapMap-YRI.

${ }^{\mathrm{h}}$ Reference values for ss218528824 from pilot_1_YRI_low_coverage_panel.

TABLE 3: Correlations (Spearman's; $r_{s}$ ) between age, gender, body mass index (BMI), alcohol consumption, smoking, total Hg in blood (THgB) and total $\mathrm{Hg}$, methylmercury, and inorganic $\mathrm{Hg}$ in plasma (THgP, MeHgP, and IHgP, resp.).

\begin{tabular}{lccccccccccc}
\hline & Age & Gender & BMI & Fish intake & Alcohol & Smoking & THgB & THgP & THgP/THgB & MeHgP & IHgP \\
\hline Age & - & -0.13 & 0.18 & -0.17 & -0.20 & -0.16 & $0.27^{*}$ & $0.21^{*}$ & -0.16 & 0.059 & $0.27^{*}$ \\
Gender $^{\mathrm{a}}$ & -0.13 & - & 0.051 & $-0.32^{* *}$ & -0.030 & 0.19 & -0.11 & -0.036 & 0.13 & 0.057 & -0.12 \\
BMI & 0.18 & 0.051 & - & -0.15 & 0.12 & 0.022 & -0.072 & 0.0090 & 0.071 & -0.075 & 0.12 \\
Fish intake & -0.17 & -0.32 & -0.15 & - & 0.12 & -0.030 & 0.20 & 0.21 & -0.075 & $0.32^{* *}$ & -0.0090 \\
Alcohol & -0.20 & -0.030 & 0.12 & 0.12 & - & 0.16 & -0.077 & 0.086 & 0.17 & 0.096 & 0.041 \\
Smoking & -0.16 & 0.19 & 0.022 & -0.030 & 0.16 & - & -0.043 & -0.12 & -0.032 & -0.098 & -0.060 \\
THgB & $0.27^{*}$ & -0.11 & -0.072 & 0.20 & -0.077 & -0.043 & - & $0.66^{* *}$ & $0.71^{* *}$ & $0.61^{* *}$ & $0.48^{* *}$ \\
THgP & $0.21^{*}$ & -0.036 & 0.0090 & 0.21 & 0.086 & -0.12 & $0.66^{* *}$ & - & 0.040 & $0.81^{* *}$ & $0.77^{* *}$ \\
THgP/THgB & -0.16 & 0.13 & 0.071 & -0.075 & 0.17 & -0.032 & $0.71^{* *}$ & 0.040 & - & -0.11 & 0.11 \\
MeHgP & 0.059 & 0.057 & -0.075 & $0.32^{* *}$ & 0.096 & -0.098 & $0.61^{* *}$ & $0.81^{* *}$ & -0.11 & - & $0.32^{* *}$ \\
IHgP & $0.27^{*}$ & -0.12 & 0.12 & -0.0090 & 0.041 & -0.060 & $0.48^{* *}$ & $0.77^{* *}$ & 0.11 & $0.32^{* *}$ & - \\
\hline
\end{tabular}

${ }^{a}$ Female was considered as reference. ${ }^{b}$ Fisk intake ranged from one to four portions per day.

${ }^{*}$ Statistically significant $P<0.050 ;{ }^{* *}$ statistically significant $P<0.010$.

that participants with the GSTM1 null genotype had higher levels of THgB and IHgP than subjects that expressed the enzyme. Also, persons carrying at least one allele T for GCLC had higher levels of THgP, MeHgP and IHgP compared to those with the nonvariant genotype, while polymorphic GLCM individuals had lower percentage of THgP in the blood stream.

Table 5 summarizes the genetic effects obtained from multivariate regressions for concentrations of $\mathrm{Hg}$ biomarkers, adjusted for fish intake, gender, and age. GSTM1 and GCLC polymorphisms modified $\mathrm{THgP}$ and $\mathrm{MeHgP}$ (multivariate analyses, $P<0.050)$. Null homozygotes for GSTM1 accumulated more THgP and MeHgP compared to subjects with GSTM1 ( $\beta=0.22, P=0.035$ and $\beta=0.30, P=0.050$, resp.).
Genetic effects were also seen concerning GCLs polymorphisms. Persons who are carrying at least one $\mathrm{T}$ allele for GCLC had higher THgP as well as MeHgP concentration $(\beta=$ $0.45, P=0.046 ; \beta=0.69, P=0.038$, resp.). Interestingly, GCLM polymorphism altered the relation between the levels of THgP and THgB; that is, participants who carried the polymorphic allele tended to have lower levels of THgP than those with the nonvariant genotype $(\beta=-0.21, P=0.050)$ (Figure 2).

\section{Discussion}

The present work shows that polymorphisms in glutathionerelated genes modify the relationship between exposure to 


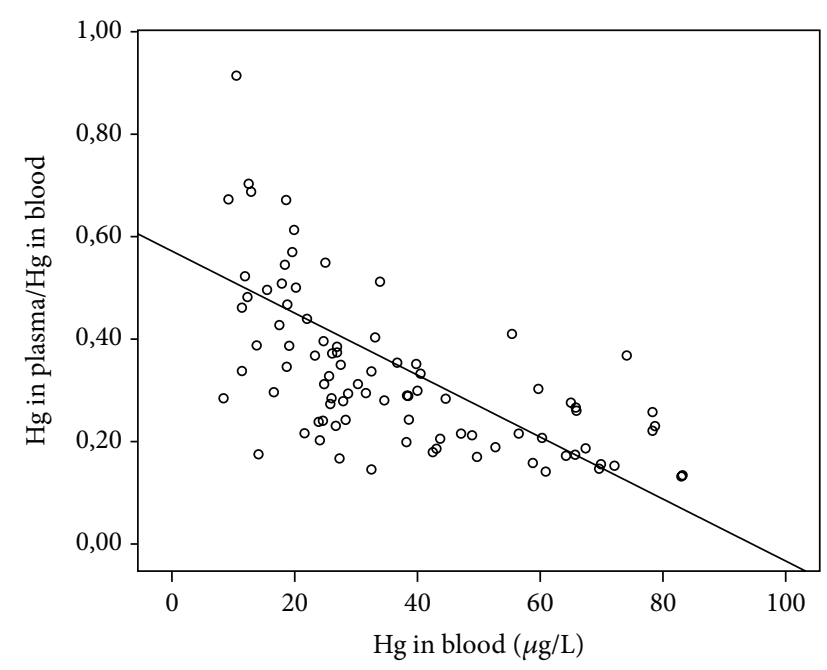

FIGURE 1: Correlation between total mercury in blood and the $\mathrm{Hg}$ in plasma/Hg in blood (Spearman's; $r_{s} 0.71, P<0.0010$ ).

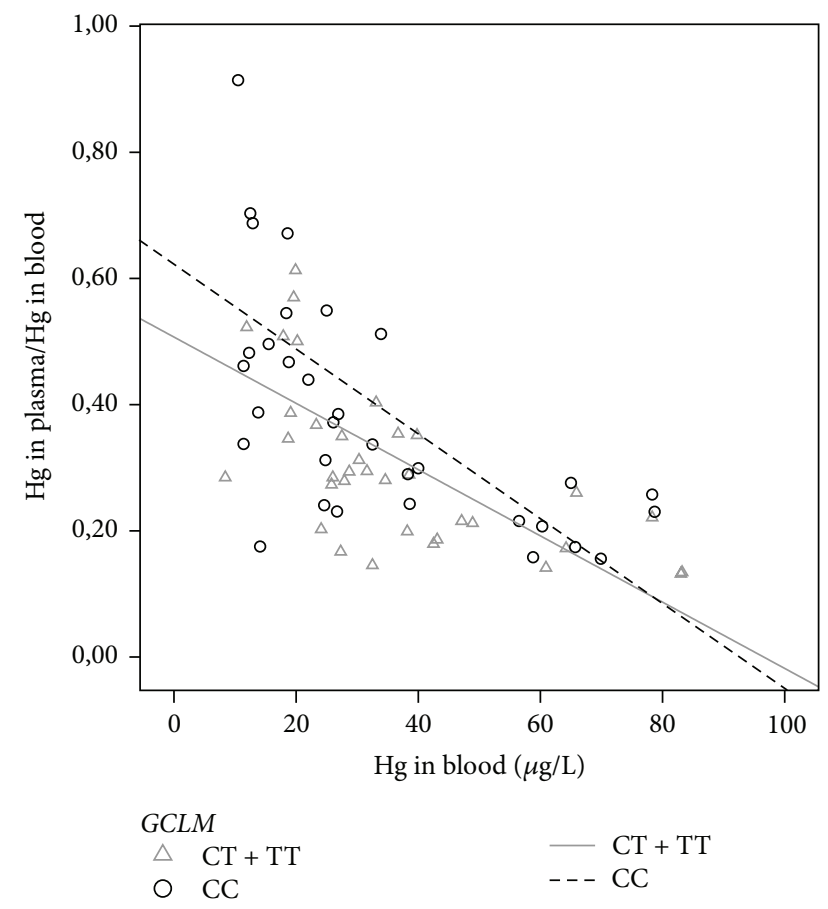

FIGURE 2: $\mathrm{Hg}$ in blood as a function of $\mathrm{Hg}$ in plasma/Hg in blood for GCLM genotypes. The regression lines do not reflect adjustments for age and gender as described in the text.

the metal and $\mathrm{Hg}$ species in plasma in a population highly exposed, via fish intake.

Correlations between fish intake and $\mathrm{MeHgP}$ were found, indicating that the populations are exposed predominantly to MeHg. However, significant correlations were not found between fish consumption and $\mathrm{THgB}, \mathrm{THgP}$, and $\mathrm{IHgP}$. Accessing the association between the exposure to $\mathrm{MeHg}$ and retention requires estimates of both. The exposure to $\mathrm{MeHg}$ depends on both the intake of fish and the concentration of the metal in the fish. Here, only data about fish intake collected by questionnaire was used and therefore, the variation of $\mathrm{Hg}$ levels in the fish, which was not estimated in this study, can be seen in the differences found in the correlations between fish consumption and $\mathrm{Hg}$ biomarkers (Table 3). Our group has previously found that $\mathrm{MeHgP}$ are associated with fish intake, while $\mathrm{IHgP}$ is not; the increase of IHgP was attributed to age and it is supposed that other processes of demethylation may be also evolved (data not published). However, we believe that other variations, such as genetic effects, are also associated with $\mathrm{Hg}$ metabolism and may explain part of this scenario.

According to the World Health Organization [33], after the ingestion of fish contaminated, approximately $95 \%$ of $\mathrm{Hg}$ is absorbed in the gastrointestinal tract resulting in 5\% of $\mathrm{Hg}$ in the blood compartment and the ratio between $\mathrm{THgP}$ and $\mathrm{THgB}$ is $1 / 20$ [34]. However low, $\mathrm{Hg}$ in plasma is the bioavailable fraction and may be related to increase of adverse health effects. However, nothing has been explored considering the effects of chemical forms of $\mathrm{Hg}$, mainly in the plasma compartment as well as their usefulness to assess toxicological risks.

We observed a negative correlation between $\mathrm{THgB}$ and $\mathrm{THgP} / \mathrm{THgB}$; that is, with increase of $\mathrm{THgB}$, a decrease in the ratio $\mathrm{THgP} / \mathrm{THgB}$ is observed, indicating that even with the increase of $\mathrm{THgB}$, saturation effects of erythrocytes do not occur, and therefore, there is no $\mathrm{Hg}$ mobilization of erythrocytes to the plasma fraction. In blood, $\mathrm{MeHg}$ is predominantly bound to erythrocytes, while $\mathrm{IHg}$ is mostly in plasma. When the exposure is to $\mathrm{IHg}$, the increase of $\mathrm{THgP}$ is independent of the concentration of $\mathrm{THgB}$, since IHg binds weakly to red blood cells $[15,20,22]$; our data give further support to these previous findings, since we observed a strong correlation between $\mathrm{THgB}$ and $\mathrm{THgP}$. Therefore, our results suggest that determination of $\mathrm{Hg}$ in total blood may not predict directly the toxicity in individuals predominantly exposed to $\mathrm{MeHg}$ and alternative approaches to assess the toxicological effects associated with $\mathrm{MeHg}$ exposure should be strongly encouraged.

As mentioned above, THgP levels are highly correlated to $\mathrm{MeHgP}$; therefore, the changes in $\mathrm{THgP}$ probably are associated to the alterations in MeHgP. We found higher concentrations of MeHgP among GSTM1 null participants, which may be related to lower MeHg-conjugating activity, lower $\mathrm{MeHg}$ excretion, and a higher $\mathrm{MeHg}$ retention.

Earlier findings of our group have also found associations between THgB and GSTM1 polymorphisms [22, 23], which were not supported in the present study; these differences between our studies may be explained by the size of the sample, which is reduced here, but not limiting for geneenvironment interactions studies. In studies of Swedish populations exposed to $\mathrm{MeHg}$ via fish intake and to $\mathrm{IHg}$ by gold mining activity, Custodio et al. $[24,25]$ found no associations between GSTM1 and concentrations of $\mathrm{Hg}$ in blood. On the other hand, Lee et al. [27] evaluated 417 pregnant women of North Korea exposed to $\mathrm{MeHg}$ via fish consumption and observed that women who had homozygous deletion for GSTM1 had higher Hg levels in blood, either during the early or late pregnancy ( $\mathrm{Hg}$ in blood 3.7 and $3.3 \mu \mathrm{g} / \mathrm{L}$, resp.), than persons with the gene. 
TABLE 4: Total Hg in blood (THgB) and total Hg, methylmercury, and inorganic Hg in plasma (THgP, MeHgP, and IHgP, resp.) as well as the ratio $\mathrm{THgP} / \mathrm{THgB}$ among the different genotypes.

\begin{tabular}{|c|c|c|c|c|c|}
\hline Genotypes & $\begin{array}{c}\text { THgB } \\
\text { Mean } \pm \text { SD }^{\mathrm{d}}\end{array}$ & $\begin{array}{c}\text { THgP } \\
\text { Mean } \pm \text { SD }\end{array}$ & $\begin{array}{c}\mathrm{MeHgP} \\
\text { Mean } \pm \text { SD } \\
\end{array}$ & $\begin{array}{c}\text { IHgP } \\
\text { Mean } \pm \text { SD }\end{array}$ & $\begin{array}{c}\text { THgP/THgB } \\
\text { Mean } \pm \mathrm{SD}\end{array}$ \\
\hline GSTM1 & $37 \pm 21$ & $10 \pm 4.4$ & $4.4 \pm 2.5$ & $5.9 \pm 2.4$ & $0.33 \pm 0.16$ \\
\hline Present & $34 \pm 18$ & $9.6 \pm 4.2$ & $4.1 \pm 2.8$ & $5.5 \pm 2.2$ & $0.33 \pm 0.14$ \\
\hline Null & $44 \pm 24$ & $12 \pm 4.7^{*}$ & $5.1 \pm 3.2$ & $6.6 \pm 2.5^{*}$ & $0.34 \pm 0.18$ \\
\hline GSTT1 & $37 \pm 21$ & $10 \pm 4.4$ & $4.4 \pm 2.9$ & $5.9 \pm 2.4$ & $0.33 \pm 0.16$ \\
\hline Present & $35 \pm 22$ & $9.9 \pm 4.6$ & $4.1 \pm 3.1$ & $5.7 \pm 2.4$ & $0.34 \pm 0.17$ \\
\hline Null & $40 \pm 19$ & $11 \pm 4.1$ & $5.0 \pm 2.7$ & $6.0 \pm 2.3$ & $0.31 \pm 0.13$ \\
\hline$G S T P 1^{\mathrm{a}}$ & $38 \pm 21$ & $10 \pm 4.0$ & $4.3 \pm 2.5$ & $5.8 \pm 2.3$ & $0.32 \pm 0.16$ \\
\hline Ile/Ile & $40 \pm 22$ & $11 \pm 3.7$ & $4.5 \pm 2.3$ & $6.1 \pm 2.4$ & $0.33 \pm 0.15$ \\
\hline $\mathrm{Ile} / \mathrm{Val}+\mathrm{Val} / \mathrm{Val}$ & $36 \pm 20$ & $9.8 \pm 3.9$ & $4.2 \pm 2.6$ & $5.6 \pm 2.2$ & $0.31 \pm 0.16$ \\
\hline$G C L M^{\mathrm{b}}$ & $35 \pm 20$ & $9.7 \pm 3.7$ & $4.2 \pm 2.3$ & $5.6 \pm 2.2$ & $0.34 \pm 0.16$ \\
\hline $\mathrm{CC}$ & $33 \pm 21$ & $10 \pm 4.1$ & $4.5 \pm 2.4$ & $5.7 \pm 2.6$ & $0.38 \pm 0.16$ \\
\hline $\mathrm{CT}+\mathrm{TT}$ & $36 \pm 19$ & $9.4 \pm 3.2$ & $3.9 \pm 2.3$ & $5.5 \pm 1.7$ & $0.30 \pm 0.13^{*}$ \\
\hline$G C L C^{\mathrm{c}}$ & $35 \pm 19$ & $9.9 \pm 4.3$ & $4.3 \pm 3.0$ & $5.6 \pm 2.2$ & $0.34 \pm 0.15$ \\
\hline CC & $34 \pm 20$ & $9.7 \pm 4.1$ & $4.1 \pm 2.9$ & $5.5 \pm 2.1$ & $0.33 \pm 0.16$ \\
\hline $\mathrm{CT}+\mathrm{TT}$ & $42 \pm 12$ & $15 \pm 6.2^{*}$ & $6.9 \pm 3.2^{*}$ & $8.1 \pm 3.1^{*}$ & $0.36 \pm 0.13$ \\
\hline
\end{tabular}

${ }^{\mathrm{a}} \mathrm{rs1695;}{ }^{\mathrm{b}} \mathrm{rs} 41307970 ;{ }^{\mathrm{c}} \mathrm{rs} 17883901 ;{ }^{\mathrm{d}}$ arithmetic mean \pm standard deviation (SD).

${ }^{*}$ indicates significant difference between the wild genotypes and the polymorphic ones (Student's $t$-test; $P<0.050$ ).

TABLE 5: Multivariate regression parameters for the associations between genotype and total $\mathrm{Hg}$ in blood ( $\mathrm{THgB}$ ) and total $\mathrm{Hg}$, methylmercury, and inorganic $\mathrm{Hg}$ in plasma (THgP, MeHgP, and IHgP, resp.) as well as the ratio THgP/THgB.

\begin{tabular}{|c|c|c|c|c|c|c|c|c|c|c|}
\hline \multirow{2}{*}{ Genotypes } & \multicolumn{2}{|c|}{$\mathrm{THgB}^{\mathrm{d}}$} & \multicolumn{2}{|c|}{$\mathrm{THgP}^{\mathrm{d}}$} & \multicolumn{2}{|c|}{$\mathrm{MeHgP}^{\mathrm{d}}$} & \multicolumn{2}{|c|}{$\mathrm{IHgP}^{\mathrm{d}}$} & \multicolumn{2}{|c|}{$\mathrm{THgP} / \mathrm{THgB}^{\mathrm{d}}$} \\
\hline & $\beta^{e}$ & $P$ & $\beta$ & $P$ & $\beta$ & $P$ & $\beta$ & $P$ & $\beta$ & $P$ \\
\hline \multicolumn{11}{|l|}{ GSTM1 } \\
\hline Present & - & - & - & - & - & - & - & - & - & - \\
\hline Null & 0.21 & 0.13 & 0.22 & 0.035 & 0.30 & 0.050 & 0.18 & 0.10 & 0.16 & 0.88 \\
\hline \multicolumn{11}{|l|}{ GSTT1 } \\
\hline Present & - & - & - & - & - & - & - & - & - & - \\
\hline Null & 0.14 & 0.31 & 0.10 & 0.34 & 0.18 & 0.24 & 0.090 & 0.45 & -0.040 & 0.71 \\
\hline \multicolumn{11}{|l|}{$G S T P 1^{\mathrm{a}}$} \\
\hline Ile/Ile & - & - & - & - & - & - & - & - & - & - \\
\hline $\mathrm{Ile} / \mathrm{Val}+\mathrm{Val} / \mathrm{Val}$ & -0.10 & 0.49 & -0.12 & 0.27 & -0.79 & 0.59 & -0.11 & 0.36 & -0.018 & 0.87 \\
\hline \multicolumn{11}{|l|}{$G_{C L M}^{\mathrm{b}}$} \\
\hline $\mathrm{CC}$ & - & - & - & - & - & - & - & - & - & - \\
\hline $\mathrm{CT}+\mathrm{TT}$ & 0.12 & 0.38 & -0.08 & 0.41 & -0.16 & 0.29 & -0.020 & 0.88 & -0.21 & 0.050 \\
\hline \multicolumn{11}{|l|}{$G C L C^{c}$} \\
\hline $\mathrm{CC}$ & - & - & - & - & - & - & - & - & - & - \\
\hline $\mathrm{CT}+\mathrm{TT}$ & 0.34 & 0.25 & 0.45 & 0.046 & 0.69 & 0.038 & 0.36 & 0.14 & 0.12 & 0.61 \\
\hline
\end{tabular}

${ }^{\mathrm{a}} \mathrm{rs1695;}{ }^{\mathrm{b}}$ rs41307970; ${ }^{\mathrm{c}} \mathrm{rs17883901;}{ }^{\mathrm{d}}$ Natural ln-transformed.

${ }^{\mathrm{e}}$ Unstandardized beta $(\beta)$ coefficients for the $\beta_{1} \times$ genotype term (categorical) adjusted for covariates. The genotype denoted first is used as reference. Multivariate model: $\mathrm{Hg}$ biomarkers $=\alpha+\beta_{1} \times$ genotype $+\beta_{2} \times$ fish intake $+\beta_{3} \times$ age $+\beta_{4} \times$ gender.

The different results between the studies might be related to different levels of $\mathrm{MeHg}$ exposure. The studies of Gundacker et al. [35], Custodio et al. [24], and Engström et al. [28] were performed on study participants with lower $\mathrm{MeHg}$ exposure than the study carried by Lee et al. [27] and our earlier study $[22,23]$. Another hypothesis is that the differences also may be explained, in some extent, to the biomarker used in the studies; however, as mentioned above, currently there is no data concerning assessment of genetic effects on $\mathrm{Hg}$ species in plasma.

We did not find association between GSTT1 polymorphism and THgP, MeHgP, and IHgP levels. An earlier work showed the GSTT1 null polymorphisms are associated with accumulation of $\mathrm{Hg}$ in individuals exposed to $\mathrm{EtHg}$ via vaccines [36]. According to Custodio et al. [24], the dealkylation of EtHg occurs faster than $\mathrm{MeHg}$ and therefore, the genetic effects may thus affect the elimination of $\mathrm{IHg}$, a point which was not observed in a further study of the same group [25] and, also, in the present work. However, in a previous work, we observed an association between THgB and GSTT1 polymorphisms [22] in the same studied population. Thus, these data bring some pieces of evidence that the genetic effects of GSTT1 may be more associated with the bioavailable $\mathrm{MeHg}$ or other organic forms than the levels of exposure to $\mathrm{Hg}$ as well as the exposure to IHg.

Also, in the present work, association between polymorphism of GSTP1 and $\mathrm{Hg}$ biomarkers was not found. Actually, 
a recent experimental study demonstrated that the Ile allele is more sensitive to $\mathrm{Hg}$ exposure. Goodrich and Basu [37] evaluated the activity of allozymes of GSTP1 towards IHg and $\mathrm{MeHg}$ and found that the GSTP1 Val allozyme was less sensitive to inhibition induced by treatment of high doses of $\mathrm{Hg}$ than the Ile allozyme. In support of this data, previous in vitro studies have suggested that ${ }^{*} 105 \mathrm{Val}$ amino acid may confer protection against $\mathrm{Hg}$-induced inhibition due to structural changes in cysteine residues which may impact the ability of $\mathrm{Hg}$ to bind and, consequently, inhibit the enzyme $[38,39]$.

GCLM polymorphism did not impact the concentrations of $\mathrm{Hg}$ biomarkers but altered the percentage of THgP in the blood stream (as seen in Figure 2). A previous work of our group [23] showed that polymorphic individuals for GCLM had lower THgB levels than those who carried at least one C-allele. However, although these polymorphic individuals had lower THgB levels, they tended to have more THgP, which may modulate the adverse health effects related to $\mathrm{MeHg}$ exposure. Moreover, variation in GCLC gene influences the levels of MeHgP. Here, we found that T-carriers for GCLC allele had significant higher levels of MeHgP than subjects with the nonvariant genotype. These data suggest that polymorphisms in GCLs may be related to biomarkers for $\mathrm{Hg}$ as well the species of the metal; also, interindividuals variations may be considered. For example, Engström et al. [28] found that Swedish persons with GCLM CC genotype had lower THgB concentrations than those who carried at least one $\mathrm{T}$ allele, whereas Custodio et al. [24] did not find any association at lower $\mathrm{MeHg}$ exposure, in same studied populations. Interestingly, in the same work, authors showed that carriers of T allele for GCLC had lower concentrations of $\mathrm{Hg}$ in erythrocytes than CC subjects, a contradictory result compared to our present.

To our knowledge, this work is the first to investigate the genetic effects of $\mathrm{Hg}$ species on plasma. Taken together, our results indicate that GSH-related polymorphisms may influence levels of $\mathrm{Hg}$ fractions in plasma, which may modulate Hg-induced toxicity. However, further studies concerning both $\mathrm{Hg}$ species in plasma as well as genetic effects are necessary for a better elucidation of the mechanisms evolved in $\mathrm{Hg}$ species metabolism.

\section{Conflict of Interests}

The authors declare that there is no conflict of interests regarding the publication of this paper.

\section{Acknowledgments}

We would like to thank São Paulo Foundation Research (FAPESP), National Counsel of Technological and Scientific Development $(\mathrm{CNPq})$, and Coordination for the Improvement of Higher Level Education Personnel (CAPES) for financial support.

\section{References}

[1] S. A. Counter and L. H. Buchanan, "Mercury exposure in children: a review," Toxicology and Applied Pharmacology, vol. 198, no. 2, pp. 209-230, 2004.

[2] C. Johansson, A. F. Castoldi, N. Onishchenko, L. Manzo, M. Vahter, and S. Ceccatelli, "Neurobehavioural and molecular changes induced by methylmercury exposure during development," Neurotoxicity Research, vol. 11, no. 3-4, pp. 241-260, 2007.

[3] M. R. Karagas, A. L. Choi, E. Oken et al., "Evidence on the human health effects of low-level methylmercury exposure," Environmental Health Perspectives, vol. 120, pp. 799-806, 2012.

[4] M. Ni, X. Li, J. B. Rocha et al., "Glia and methylmercury neurotoxicity," Journal of Toxicology and Environmental Health A, vol. 75, no. 16-17, pp. 1091-1101, 2012.

[5] A. L. Choi, P. Weihe, E. Budtz-Jørgensen et al., "Methylmercury exposure and adverse cardiovascular effects in Faroese Whaling men," Environmental Health Perspectives, vol. 117, no. 3, pp. 367372, 2009.

[6] M. C. Houston, "Role of mercury toxicity in hypertension, cardiovascular disease, and stroke," Journal of Clinical Hypertension, vol. 13, no. 8, pp. 621-627, 2011.

[7] Agency for Toxic Substances and Diseases Control (ATSDR), Toxicological Profile for Mercury, U.S. Department of Health and Human Services, Public Health Service, Washington, DC, USA, 1999.

[8] C. J. Passos and D. Mergler, "Human mercury exposure and adverse health effects in the Amazon: a review," Cadernos de Saude Publica, vol. 24, no. 4, pp. S503-S520, 2008.

[9] K. L. Caldwell, M. E. Mortensen, R. L. Jones, S. P. Caudill, and J. D. Osterloh, "Total blood mercury concentrations in the U.S. population: 1999-2006," International Journal of Hygiene and Environmental Health, vol. 212, no. 6, pp. 588-598, 2009.

[10] M. F. Carneiro, D. Grotto, B. L. Batista, C. R. Rhoden, and F. Barbosa Jr., "Background values for essential and toxic elements in children's nails and correlation with hair levels," Biological Trace Element Research, vol. 144, no. 1-3, pp. 339-350, 2011.

[11] J. F. Nyland, M. Fillion, F. Barbosa Jr. et al., "Biomarkers of methylmercury exposure immunotoxicity among fish consumers in amazonian Brazil," Environmental Health Perspectives, vol. 119, no. 12, pp. 1733-1738, 2011.

[12] S. M. Vieira, R. de Almeida, I. B. Holanda et al., "Total and methyl-mercury in hair and milk of mothers living in the city of Porto Velho and in villages along the Rio Madeira, Amazon, Brazil," International Journal of Hygiene and Environmental Health, vol. 216, no. 6, pp. 682-689, 2013.

[13] World Health Organization (WHO), International Programme on Chemical Safety (IPCS)-Environmental Health Criteria 155: Biomarkers and Risk Assessment: Concepts and Principles, World Health Organization, Geneva, Switzerland, 1993.

[14] F. L. Lorscheider, M. J. Vimy, and A. O. Summers, "Mercury exposure from "silver" tooth firings: emerging evidence questions a traditional dental paradigm," FASEB Journal, vol. 9, no. 7, pp. 504-508, 1995.

[15] T. W. Clarkson, J. B. Vyas, and N. Ballatori, "Mechanisms of mercury disposition in the body," American Journal of Industrial Medicine, vol. 50, no. 10, pp. 757-764, 2007.

[16] S. Ancora, R. Rossi, P. Di Simplicio, L. Lusini, and C. Leonzio, "In Vitro study of methylmercury in blood of bottlenose dolphins (Tursiops truncatus)," Archives of Environmental Contamination and Toxicology, vol. 42, no. 3, pp. 348-353, 2002. 
[17] K. C. de Marco, G. U. Braga, and F. Barbosa Jr., "Determination of the effects of eNOS gene polymorphisms (T-786C and $\mathrm{Glu}^{298} \mathrm{Asp}$ ) on nitric oxide levels in a methylmercury-exposed population," Journal of Toxicology and Environmental Health A, vol. 74, no. 20, pp. 1323-1333, 2011.

[18] D. Grotto, J. Valentini, M. Fillion et al., "Mercury exposure and oxidative stress in communities of the Brazilian Amazon," Science of the Total Environment, vol. 408, no. 4, pp. 806-811, 2010.

[19] M. Berglund, B. Lind, K. A. Björnberg, B. Palm, Ö. Einarsson, and M. Vahter, "Inter-individual variations of human mercury exposure biomarkers: a cross-sectional assessment," Environmental Health, vol. 3, pp. 4-20, 2005.

[20] T. W. Clarkson and L. Magos, "The toxicology of mercury and its chemical compounds," Critical Reviews in Toxicology, vol. 36, no. 8, pp. 609-662, 2006.

[21] C. Gundacker, M. Gencik, and M. Hengstschläger, "The relevance of the individual genetic background for the toxicokinetics of two significant neurodevelopmental toxicants: mercury and lead," Mutation Research, vol. 705, no. 2, pp. 130-140, 2010.

[22] G. R. M. Barcelos, K. C. de Marco, D. Grotto et al., "Evaluation of glutathione S-transferase i and GSTT1 polymorphisms and methylmercury metabolism in an exposed Amazon population," Journal of Toxicology and Environmental Health A, vol. 75, no. 16-17, pp. 960-970, 2013.

[23] G. R. M. Barcelos, D. Grotto, K. C. de Marco et al., "Polymorphisms in glutathione-related genes modify mercury concentrations and antioxidant status in subjects environmentally exposed to methylmercury," Science of Total Evironment, vol. 463-464, pp. 319-325, 2013.

[24] H. M. Custodio, K. Broberg, M. Wennberg et al., "Polymorphisms in glutathione-related genes affect methylmercury retention," Archives of Environmental Health, vol. 59, no. 11, pp. 588595, 2004.

[25] H. M. Custodio, R. Harari, L. Gerhardsson, S. Skerfving, and K. Broberg, "Genetic influences on the retention of inorganic mercury," Archives of Environmental and Occupational Health, vol. 60, no. 1, pp. 17-23, 2005.

[26] C. Gundacker, K. J. Wittmann, M. Kukuckova et al., "Genetic background for mercury metabolism," Toxicology Letters, vol. 189, pp. S89-S90, 2009.

[27] B. Lee, Y. Hong, H. Park et al., "Interaction between GSTM1/ GSTT1 polymorphism and blood mercury on birth weight," Environmental Health Perspectives, vol. 118, no. 3, pp. 437-443, 2010.

[28] K. S. Engström, U. Strömberg, T. Lundh et al., "Genetic variation in glutathione-related genes and body burden of methylmercury," Environmental Health Perspectives, vol. 116, no. 6, pp. 734-739, 2008.

[29] C. J. Passos, D. Mergler, M. Fillion et al., "Epidemiologic confirmation that fruit consumption influences mercury exposure in riparian communities in the Brazilian Amazon," Environmental Research, vol. 105, no. 2, pp. 183-193, 2007.

[30] S. S. Souza, A. D. Campiglia, and F. Barbosa Jr., "A simple method for methylmercury, inorganic mercury and ethylmercury determination in plasma samples by high performance liquid chromatography-cold-vapor-inductively coupled plasma mass spectrometry," Analytica Chimica Acta, vol. 761, pp. 11-17, 2013.

[31] S. Z. Abdel-Rahman, R. A. El-Zein, W. A. Anwar, and W. W. $\mathrm{Au}$, "A multiplex PCR procedure for polymorphic analysis of GSTM1 and GSTT1 genes in population studies," Cancer Letters, vol. 107, no. 2, pp. 229-233, 1996.
[32] Z. Mo, Y. Gao, Y. Cao, F. Gao, and L. Jian, "An updating metaanalysis of the GSTM1, GSTT1, and GSTP1 polymorphisms and prostate cancer: a HuGE review," Prostate, vol. 69, no. 6, pp. 662688, 2009.

[33] World Health Organization (WHO), Environmental Health Criteria 101: Methylmercury, World Health Organization, Geneva, Switzerland, 1990.

[34] T. W. Clarkson, “The three modern faces of mercury," Environmental Health Perspectives, vol. 110, no. 1, pp. 11-23, 2002.

[35] C. Gundacker, G. Komarnicki, P. Jagiello et al., "GlutathioneS-transferase polymorphism, metallothionein expression, and mercury levels among students in Austria," Science of the Total Environment, vol. 385, no. 1-3, pp. 37-47, 2007.

[36] G. A. Westphal, A. Schnuch, T. G. Schulz et al., "Homozygous gene deletions of the glutathione S-transferases $\mathrm{M} 1$ and $\mathrm{T} 1$ are associated with thimerosal sensitization," International Archives of Occupational and Environmental Health, vol. 73, no. 6, pp. 384-388, 2000.

[37] J. M. Goodrich and N. Basu, "Variants of glutathione s-transferase pi 1 exhibit differential enzymatic activity and inhibition by heavy metals," Toxicology in Vitro, vol. 26, no. 4, pp. 630-635, 2012.

[38] M. M. Almar and P. J. Dierickx, "In Vitro interaction of mercury, copper (II) and cadmium with human glutathione transferase $\pi$," Research Communications in Chemical Pathology and Pharmacology, vol. 69, no. 1, pp. 99-102, 1990.

[39] P. J. Dierickx, "In Vitro inhibition of the soluble glutathione Stransferases from rat liver by heavy metals," Enzyme, vol. 27, no. 1, pp. 25-32, 1982. 

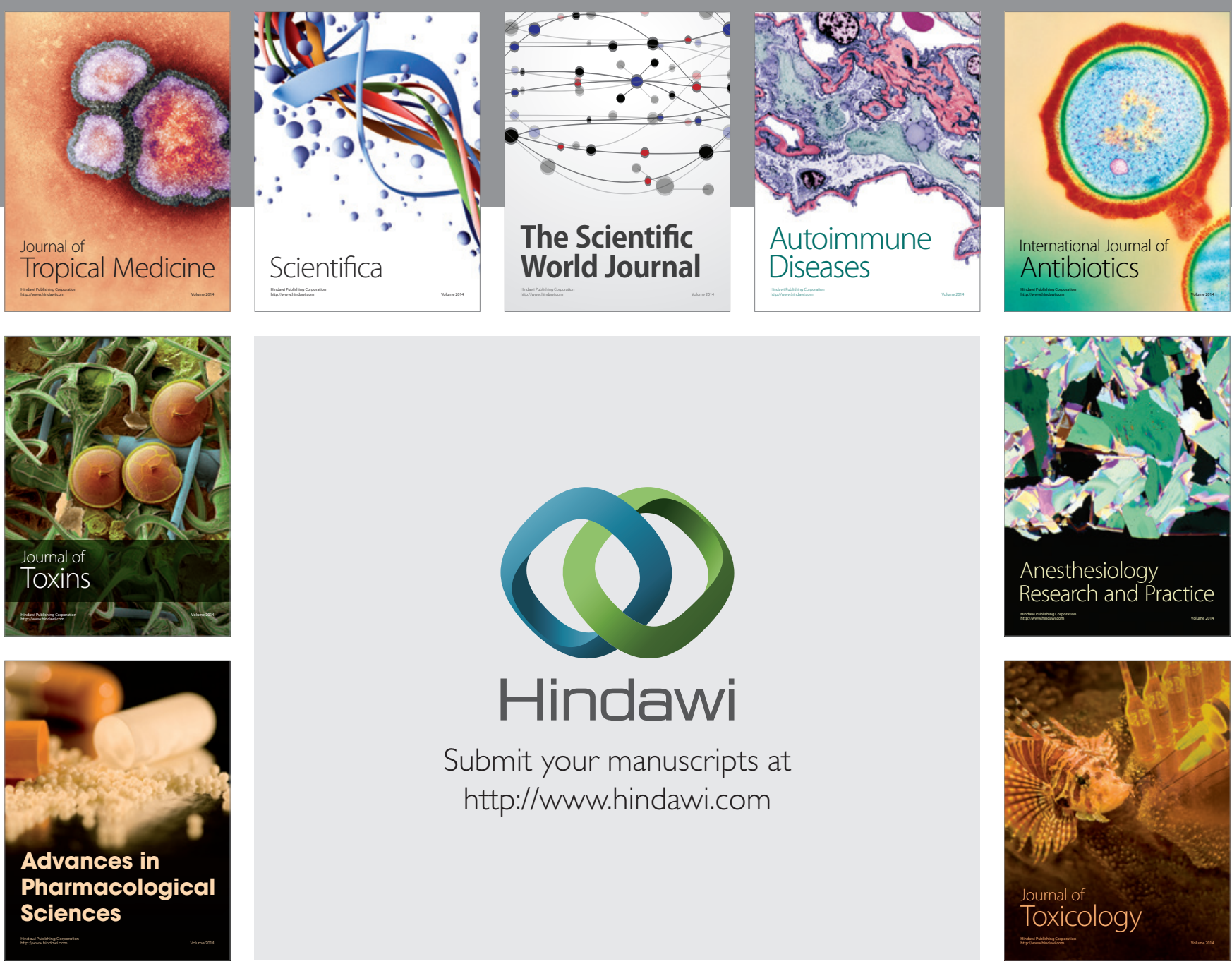

\section{Hindawi}

Submit your manuscripts at

http://www.hindawi.com
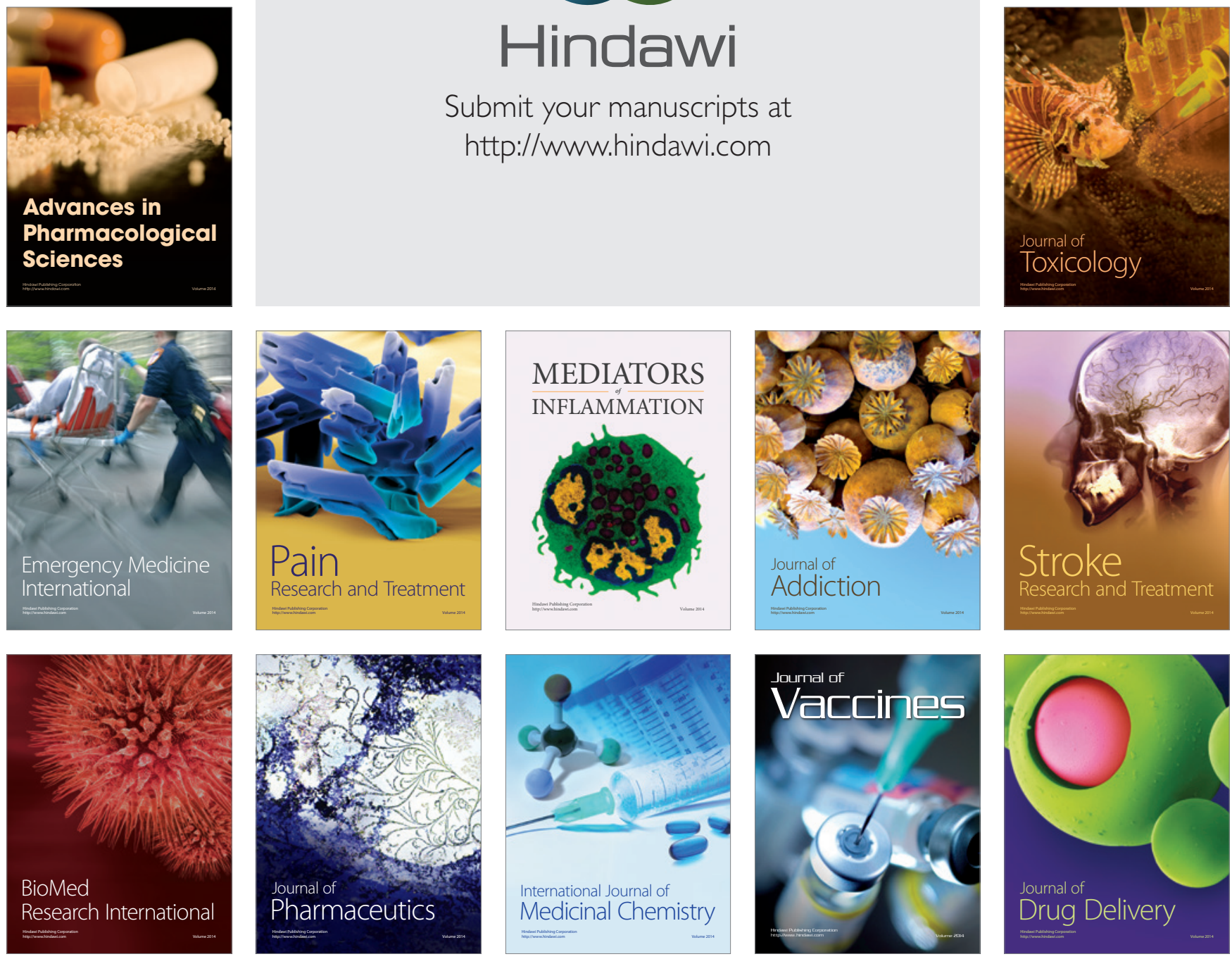